\title{
Diversity and Plasticity of Self Recognition during the Development of Multiple Sclerosis
}

\author{
Vincent K. Tuohy, ${ }^{\star \ddagger}$ Min Yu, ${ }^{*}$ Bianca Weinstock-Guttman, ${ }^{\ddagger}$ and R. Philip Kinkel ${ }^{\ddagger}$ \\ *Department of Immunology, Research Institute, and ${ }^{\ddagger}$ Mellen Center for Multiple Sclerosis Research and Treatment, The Cleveland Clinic \\ Foundation, Cleveland, Ohio 44195
}

\begin{abstract}
Recent studies using murine animal model systems indicate that clinical progression of autoimmune disease may be due to the sequential accumulation of neoautoreactivity characterized by extensive plasticity of self recognition. In the present study, we addressed the question of whether a similar paradigm of self recognition is implicated in the development of multiple sclerosis (MS), a demyelinating disease with a presumed autoimmune etiology. Our approach was to determine serial changes over a $12-18$-mo period in response to an epitope-mapping series of 265 12-mer peptides of myelin proteolipid protein (PLP) by patients with isolated monosymptomatic demyelinating syndromes (IMDS), a group of distinct clinical disorders with variable rates of progression to MS. Our data showed that an extensive array of proteolipid protein peptides could elicit autoreactivity. Moreover, differential autoreactive patterns were evident within IMDS patient subpopulations. Monocentric monophasic IMDS patients with no evidence of prior subclinical disease typically showed fully sustained autoreactivity characterized by extensive plasticity, epitope focusing, shifting, and spreading of responses to new self determinants. In contrast, multicentric monophasic IMDS patients with putative evidence of prior asymptomatic lesion formation typically showed partially sustained autoreactivity characterized by abrupt abrogation of responses to an extensive array of self determinants. No sustained autoreactivity was observed in normal control subjects or in patients with other neurologic diseases. Our results indicate that self recognition associated with the development of MS is a developmental process characterized by autoreactive diversity, plasticity, and instability. (J. Clin. Invest. 1997. 99:16821690.) Key words: autoimmunity • demyelination • myelin proteolipid protein $\bullet \mathrm{T}$ cell epitopes $\bullet$ encephalomyelitis
\end{abstract}

Address correspondence to Vincent K. Tuohy, The Cleveland Clinic Foundation, Department of Immunology, FFb-1, 9500 Euclid Avenue, Cleveland, OH 44195. Phone: 216-445-9684; FAX: 216-444-8372; E-mail: tuohyv@cesmtp.ccf.org

Received for publication 29 July 1996 and accepted in revised form 15 January 1997.

J. Clin. Invest.

(C) The American Society for Clinical Investigation, Inc.

0021-9738/97/04/1682/09 \$2.00

Volume 99, Number 7, April 1997, 1682-1690

\section{Introduction}

Although the etiology of multiple sclerosis (MS $)^{1}$ is uncertain, there is much evidence suggesting that the pathogenesis of MS involves autoimmune recognition of central nervous system (CNS) myelin proteins $(1,2)$. Numerous reports have shown that patients with established MS have T cell reactivity to a variety of myelin proteins and their peptide determinants including myelin basic protein (3-8), myelin proteolipid protein (9-11), myelin oligodendrocyte protein (12), and myelin associated glycoprotein (13).

Recent studies have shown that acquired recognition of new self determinants, a process commonly referred to as determinant spreading, accompanies the development of relapse and chronic progression of experimental autoimmune encephalomyelitis (EAE), an animal model with many similarities to MS (14-20). In addition, we have recently observed that clinical progression of EAE requires the development of a determinant spreading cascade in which a predictable sequential accumulation of neoautoreactivity occurs (20). The endogenous spreading of murine autoreactivity is characterized by an extraordinary plasticity of myelin self-determinant recognition, which can be separated into at least four components: $(a)$ recognition of broad protein regions incorporating core and flanking sequences of encephalitogenic determinants. This pattern is typically characteristic of early self-recognition events initiated by either exogenous priming or endogenous spreading; (b) focusing of recognition to core sequences within each protein region; $(c)$ shifting of epitope responses within each region; and $(d)$ spreading of the response to new regions incorporating new encephalitogenic core determinants.

The present study addresses the question of whether the development and progression of MS is characterized by a paradigm of self-recognition plasticity analogous to that occurring in EAE. Since MS typically persists for many years before a definitive diagnosis can be made, we focused our study on patients with isolated monosymptomatic demyelinating syndromes (IMDS), a group of distinct clinical disorders often associated with eventual progression to clinically definite MS (CDMS) (21-23). Recent diagnostic advances using magnetic resonance imaging (MRI) have shown that the probability for IMDS $\rightarrow$ CDMS progression is directly related to CNS lesion appearance as evaluated by MRI at onset of clinical symptoms. IMDS patients showing only the CNS lesion responsible for

1. Abbreviations used in this paper: CDMS, clinically definite multiple sclerosis; CNS, central nervous system; EAE, experimental autoimmune encephalomyelitis; IMDS, isolated monosymptomatic demyelinating syndrome; MRI, magnetic resonance imaging; MS, multiple sclerosis; NC, normal controls; OND, other neurologic diseases; PLP, myelin proteolipid protein; SI, stimulation index. 
acute symptoms (monocentric monophasic IMDS) have a $5-10 \%$ progression rate to CDMS over 2-5 yr. It is widely viewed that monocentric monophasic IMDS represents the earliest stage at which inflammatory demyelination can be followed from the genuine onset of disease. In contrast, IMDS patients showing asymptomatic CNS white matter lesions in addition to those responsible for the acute presenting symptoms (multicentric monophasic IMDS) have a relatively higher risk (50-90\%) for progressing to CDMS over 2-5 yr (21-23). It is generally acknowledged that many if not all of the asymptomatic lesions of multicentric monophasic IMDS are evidence of prior asymptomatic demyelination perhaps present for months or years before the onset of acute neurologic symptoms.

The differential risk for progression to CDMS may reflect primary and secondary developmental stages of the MS disease process in the monocentric and multicentric IMDS patient populations, respectively. Thus, in light of the putative autoimmune etiology proposed for MS $(1,2)$, it seems reasonable to consider that the development of increased risk for progression to CDMS would be accompanied by an evolving autoreactivity. To test this hypothesis, we determined changes with time in proliferative responses to an epitope-mapping PLP peptide series in IMDS patients at low vs high risk for progression to CDMS. Newly diagnosed patients were serially tested at 2-6-mo intervals over a 12-18-mo period, and disease activity was determined by serial clinical and MRI assessments over the course of the study.

Our data show that distinctly different autoreactive profiles occur in patients with monocentric monophasic vs multicentric monophasic demyelinating disease. Our results indicate that myelin self recognition during the development of MS is fundamentally an unstable and evolving process that may require a comparable degree of flexibility in developing antigen-specific peptide-targeted therapies.

\section{Methods}

Criteria for selection of test and control subjects. The development and progression of myelin self recognition was evaluated in patients with any of three well-defined, acute, isolated monosymptomatic demyelination syndromes: (a) monocular optic neuritis, $(b)$ partial transverse myelitis, and (c) brainstem syndromes. An additional patient (VS) with a symptomatic internal capsule lesion on MRI was also included in the study based on the presumed inflammatory nature of the lesion as indicated from the clinical and MRI course as well as from spinal fluid analysis. IMDS patients were separated into two groups according to the baseline appearance of cranial and spinal MRI scans: $(a)$ IMDS subjects with monocentric monophasic demyelination had normal MRI scans other than the area of abnormality responsible for their acute symptoms. Multimodal-evoked potentials were obtained in selected monocentric monophasic patients to exclude subclinical involvement of either the spinal cord or optic nerve; $(b)$ IMDS subjects with multicentric monophasic demyelination had $\geq 2$ asymptomatic white matter lesions $\geq 3 \mathrm{~mm}$ in diameter, at least one of which was periventricular in location or ovoid in shape. IMDS subjects showed no evidence by history or exam of prior CNS symptoms, or history of any systemic illness known to be associated with neurologic dysfunction or stroke. Control subjects consisted of age- and sex-matched normal control volunteers (NC) as well as young adults with organic brain damage from other neurologic diseases (OND). The OND group consisted primarily of patients with acute cerebrovascular events or injuries. OND control subjects were studied within 1 mo of ictus and were evaluated by serial blood studies only. None of the test or control subjects were pregnant, although one
IMDS subject entered the study 1 wk postpartum. All test and control subjects were able to understand informed consent and comply with the study protocol approved by the Internal Review Board of the Cleveland Clinic Foundation.

Study protocol. All IMDS subjects were seen by the study neurologist (RPK) within 2 wk of onset of symptoms and were enrolled in the current study within $3 \mathrm{mo}$. For those patients treated with corticosteroid (intravenous methylprednisolone 1 gram four times a day for $3 \mathrm{~d}$ followed by a 12-d prednisone taper), baseline blood drawing for proliferation assays was obtained before treatment. If corticosteroids were required during the course of the study, blood draws were performed either before treatment or at least 2 mo afterward. IMDS subjects were routinely examined at 2, 4, 6, 12, and 16 mo in addition to unscheduled visits for the evaluation of new symptoms. Three patients (DB, LT, LH) were unable to attend their 2-mo visits and were rescheduled for 3- and 6-mo visits to ensure an interval of at least 2 mo between blood drawing. All patients had at least three blood draws in the first 6 mo. Multicentric monophasic IMDS subjects had MRI scans of the head performed at each study visit (within $24 \mathrm{~h}$ of blood draw), and those participating in an independent serial MRI study were also seen at 9 mo. Monocentric monophasic IMDS patients had MRIs at baseline and at 6- and 12-mo visits.

Definition of disease activity. Disease activity in IMDS patients was defined as the occurrence of interval clinical or MRI activity. Clinical activity or relapse was defined as the development of new or old neurologic symptoms characteristic of MS with objective findings on neurologic exam lasting $>48 \mathrm{~h}$. Relapses were identified only if patients were stable or improved in the month before. Clinically definite MS (CDMS) was defined as a relapse involving an anatomically different area of the nervous system compared with onset symptoms (24). Interval MRI activity was defined as a gadoteridol enhancing lesion on enhanced $\mathrm{T} 1$ weighted images not present during the previous scan or an unequivocal new area of increased signal $\geq 3 \mathrm{~mm}$ in diameter on $\mathrm{T} 2$ weighted images in the absence of any gadoteridol enhancing lesions. Interval development of increased signal on T2 weighted images in areas where gadoteridol-enhancing lesions previously existed was not considered to be interval activity. MRI activity was not used to define CDMS.

MRI. MRI was performed in a 1.5 Tesla superconducting whole body imaging system (Siemens Medical System, Iselin, NJ). Repositioning error was minimized through alignment of external and internal landmarks. A sagittal T1-weighted spin echo (SE) scout acquisition $(500 \mathrm{~ms} / 15 \mathrm{~ms} / 5 \mathrm{~mm} / 2 \mathrm{~mm} / 192 \times 256 / 2 \mathrm{NEX}$; repetition time/ echo time/slice thickness/interslice gap/matrix/number of acquisitions) was initially obtained to verify head position using an internal angle. This was followed by an axial T2-weighted SE acquisition $(2,500 \mathrm{~ms} / 22 \mathrm{~ms}, 90 \mathrm{~ms} / 5 \mathrm{~mm} / 2 \mathrm{~mm} / 160 \times 256$ rectangular FOV/1NEX). The same slice positions were incorporated for the unenhanced axial T1-weighted SE study $(600 / 15 / 5 \mathrm{~mm} / 2 \mathrm{~mm} / 160 \times 256$ rectangular FOV/2NEX). Patients were then injected with $0.1 \mathrm{mmol} / \mathrm{kg}$ gadoteridol followed immediately by a second axial T1-weighted study. An additional dose of $0.2 \mathrm{mmol} / \mathrm{kg}$ gadoteridol was then injected (for a total dose of $0.3 \mathrm{mmol} / \mathrm{kg}$ ) followed immediately by the final axial $\mathrm{T} 1$ weighted study. Image analysis was performed by two neuroradiologists blinded to the clinical and immunologic disposition of the patients.

Epitope-mapping PLP peptide series. A PLP peptide series effectively representing a walk through of the entire 276 amino acid primary sequence of mouse PLP (25, 26; Fig. 1) was purchased from Chiron Mimotopes (San Diego, CA). A total of 265 overlapping 12-mers were synthesized on high-density polyethylene rod tips assembled into holders designed in 96-well microtiter plate format (27). When FMOC (9-fluorenylmethoxycarbonyl-) biochemistry is used in the synthesis, cleavage of one peptide/microtiter well can occur $(28,29)$. Peptide purity was consistently shown to be $\geq 85-90 \%$ as determined by analytical HPLC scans of benchmark and test peptides synthesized on each plate for quality control purposes. Similar pin series have been used successfully to map $\mathrm{T}$ cell determinants of hen egg-white 
lysozyme (29), myelin basic protein $(17,30)$, and glutamic acid decarboxylase (31). Upon arrival, $1 \mathrm{mg}$ of each PLP pin peptide was dissolved in $500 \mu \mathrm{l}$ of a solution of $40 \%$ acetonitrile (Aldrich Chemical, Milwaukee, WI) in $10 \mathrm{mM}$ Hepes buffer (Gibco BRL, Grand Island, $\mathrm{NY}$ ). Working aqueous concentrations of pin peptides were prepared at $150 \mu \mathrm{g} / \mathrm{ml}$ in PBS, $\mathrm{pH} 7.2$, and $20 \mu \mathrm{l}$ of each working solution was distributed sequentially into individual wells of 96-well flat-bottomed microtiter Falcon plates (Becton Dickinson and Co., Lincoln Park, $\mathrm{NJ})$. The plates were stored at $-20^{\circ} \mathrm{C}$ until ready for use.

Proliferation assays. PBMC from each IMDS subject were evaluated at baseline, 2, 4, 6, 12, and 16-18 mo for proliferative responses to the 265 overlapping PLP epitope-mapping peptides. PBMC were separated by centrifugation on Ficoll-Paque (Pharmacia Biotechnology, Uppsala, Sweden) for $25 \mathrm{~min}$ at 1,500 rpm. Cells collected from the interface were washed three times in HBSS (Gibco BRL) and resuspended in serum-free HL-1 media (Hycor, Irvine, CA) supplemented with $2 \mathrm{mM}$ fresh L-glutamine, $100 \mathrm{U} / \mathrm{ml}$ penicillin, $100 \mu \mathrm{g} / \mathrm{ml}$ streptomycin, and $30 \mathrm{mM}$ Hepes buffer. Each well contained $1 \times 10^{5}$ PBMC with $15 \mu \mathrm{g} / \mathrm{ml}$ pin peptide in a total volume of $200 \mu \mathrm{l}$. Triplicate positive control wells contained anti-human CD3 antibody at 10 $\mu \mathrm{g} / \mathrm{ml}$ (Ortho Biotechnology, Raritan, NJ), tetanus toxoid at 1:1,000 dilution (Lederle Laboratories, Pearl River, NY), or $20 \mu \mathrm{g} / \mathrm{ml} \mathrm{Myco-}$ bacteria tuberculosis H37RA (Difco Laboratories, Detroit, MI) whereas negative control wells contained either no peptide or one of 30 irrelevant pin peptides of myohemerythrin, a protein having minimal sequence homology with myelin proteins (32). Dose responses to whole bovine PLP $(0.1-100 \mu \mathrm{g} / \mathrm{ml})$ were also assessed in each experiment. The PLP was prepared from a washed total lipid extract of bovine white matter (33) and was purified and converted to aqueous form as previously described (34). Cultures were incubated at $37^{\circ} \mathrm{C}$ in humidified air containing $5 \% \mathrm{CO}_{2}$. At $72 \mathrm{~h}$, cultures were pulsed with [methyl- ${ }^{3} \mathrm{H}$ ] thymidine $(1.0 \mu \mathrm{Ci} /$ well, sp act $6.7 \mathrm{Ci} / \mathrm{mmol}$; New England Nuclear, Boston, MA), and the cells were harvested after $16 \mathrm{~h}$ by aspiration onto glass fiber filters. Levels of incorporated radioactivity were determined by scintillation spectrometry.

Criteria for identification of PLP determinants. Test wells containing $15 \mu \mathrm{g} / \mathrm{ml}$ of a single PLP peptide were considered positive with a stimulation index $\geq 2.0$ and with a $\Delta \mathrm{cpm} \geq 500$ and at least two standard deviations above the mean of unstimulated control wells. Identification of PLP antigenic determinants required that positive proliferative responses be generated to at least three adjacent overlapping 12-mers. Control subjects were similarly evaluated by multiple serial testing.

Tissue typing. High resolution DNA typing for HLA class II DR and DQ alleles was performed at the tissue typing facility of the Cleveland Clinic Foundation by sequence-specific oligonucleotide probe typing (PCR-SSOP).

Statistical analysis. The Fisher's exact test (two-sided) was used to test the association between autoreactive response patterns and evidence of prior disease activity.

\section{Results}

IMDS. PBMC responses to an epitope-mapping PLP peptide series (Fig. 1) were serially evaluated over a 12-18-mo period in patients newly diagnosed with IMDS. The IMDS study subjects included nine females and two males with a mean age of $33 \mathrm{yr}$ (range, 21-43) at onset of neurologic symptoms. 7 of 11 IMDS patients were tested within $3 \mathrm{wk}$ of initial onset of neurologic symptoms whereas the remaining four patients were evaluated within $7-10 \mathrm{wk}$ of symptom onset. The median time from onset of symptoms to study start was $10 \mathrm{~d}$.

Table I shows serial responses to PLP peptides by IMDS patients showing no abnormalities on baseline MRI scans of the CNS other than the lesion responsible for their acute symptoms. Such monocentric monophasic IMDS patients have
PLP Sequence

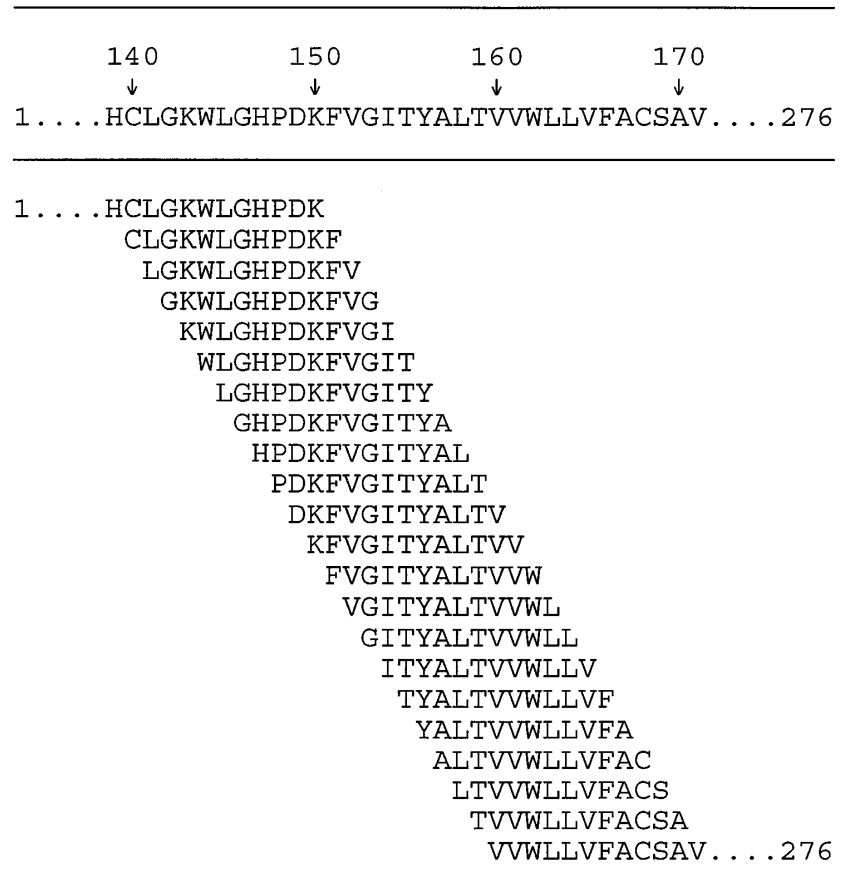

Figure 1. Epitope-mapping peptide series for PLP. An overlapping series of 12-mer peptides effectively representing a walk through of the entire 276 amino acid primary sequence of mouse PLP was used in serial evaluation of proliferative responses of PBMC from IMDS patients and controls.

been shown to have a low 5-yr risk for progression to CDMS, presumably because of no evidence of prior lesion formation (21-23). Table II shows serial autoreactivity by IMDS patients having a mean of 13.6 $\pm 5.1 \mathrm{SD}$ (range 5-22) asymptomatic T2 lesions on baseline brain MRI. Such multicentric monophasic IMDS patients have been shown to be at high risk for progression to CDMS, presumably due to prior disease activity (2123). Only two high risk subjects (JG, DB) showed asymptomatic gadoteridol enhanced lesions on baseline brain MRI. Therefore, the vast majority of asymptomatic lesions in multicentric monophasic IMDS patients were of undetermined age.

Response to myelin PLP by IMDS patients. Initial testing showed that only 4 out of 11 (36\%) IMDS subjects responded to one or more PLP peptides (Tables I and II). However, the incidence of autoreactivity increased markedly over the course of the study with 31 out of 47 (74\%) subsequent serial assays showing PLP reactivity and 10 out of 11 (91\%) IMDS patients eventually responding to one or more determinants. These data indicate that some of the IMDS patients acquired autoreactivity during the course of the study, an observation that highlights the importance of serial assessment of autoreactivity. No single dominant consensus determinant was recognized by any IMDS group. Instead, IMDS subjects responded to an extensive array of PLP peptides. With the notable exceptions of PLP 1-29 and 64-101, responses were directed against a broad range of determinants located within the remaining 276 amino acid sequence of the PLP molecule (Fig. 2).

Three distinct autoreactive profiles in IMDS. Three fundamentally distinct patterns of autoreactivity were evident in the 
responses of IMDS patients to PLP determinants, viz., (a) fully sustained responses, $(b)$ partially sustained responses, and $(c)$ ephemeral responses. Fully sustained reproducible autoreactive responses involving epitope focusing, shifting, and spreading of autoreactivity to new self determinants were particularly characteristic of and exclusively observed in monocentric monophasic IMDS patients with no evidence of prior subclinical disease and a low risk for progression to CDMS (Table I). Fully sustained autoreactivity may best be exemplified by the responses of VS and DL who showed marked plasticity in reacting to p210-244 and p116-150, respectively. In both cases, autoreactivity to a broad region of PLP was followed by focusing of recognition to core peptide sequences within each region, shifting of epitope responses within each region, and intramolecular spreading of the response to new peptide regions of PLP.

Partially sustained responses representing incomplete patterns of PLP autoreactive plasticity were particularly characteristic of multicentric monophasic IMDS patients at high risk for progression to CDMS (Table II). Such abrogated autoreactivity may best be exemplified by the PLP response profiles of
LH, LT, and SW that showed epitope focusing and shifting after initial responses to the broad PLP regions p198-232 (SI = 2.2), p188-220 (SI = 3.4), and p210-252 (SI = 6.5), respectively. However, the initial indications of self recognition plasticity were not subsequently sustained but instead were succeeded by spreading of recognition to new nonoverlapping PLP determinants. Thus, multicentric monophasic IMDS patients appeared to show self-recognition patterns in which autoreactivity appeared to slowly disappear and subsequently resurface as neoautoreactivity to distinctly different determinants. The delayed abrogation of the developing autoreactivity suggests that regulatory mechanisms may act to slowly but eventually abort ongoing established autoimmunity. No multicentric monophasic IMDS patients showed fully sustained autoreactivity. The exclusive expression of fully sustained autoreactivity in 4 out of 4 monocentric monophasic IMDS patients but not in any multicentric monophasic subjects was found to be significant $(P=0.003)$.

Ephemeral autoimmunity, characterized by isolated, nonreproduced responses to specific PLP determinants, was ob-

Table I. Serial PBMC Responses to PLP Peptides by Monocentric Monophasic IMDS Patients with No Evidence of Prior Disease Activity*

\begin{tabular}{|c|c|c|c|c|c|c|}
\hline \multicolumn{2}{|c|}{ Wk (after initial symptoms) } & \multicolumn{2}{|l|}{ PLP sequence } & \multicolumn{3}{|c|}{ Stimulation index } \\
\hline \multicolumn{7}{|c|}{ JB: 34-yr-old White male with anterior brainstem syndrome } \\
\hline \multicolumn{7}{|c|}{$117-152$} \\
\hline 7 & \multicolumn{5}{|c|}{$\ldots \ldots \ldots$. . . . . . . . . . . . } & \\
\hline 16 & \multicolumn{3}{|c|}{ TGGQKGRGSRGQHQAH - - - RVCHCLGKWLGHPDKFV } & \multicolumn{2}{|c|}{$2.4 ; 4.0$} & \\
\hline 25 & \multicolumn{3}{|c|}{ - . . . . . . . . . . RVCHCLGKWLGHPDK- - } & \multicolumn{2}{|c|}{2.2} & \\
\hline 56 & \multicolumn{3}{|c|}{ - . . . . - . - . - HSLERVCHCLGKWLGPDK - - } & \multicolumn{2}{|l|}{2.3} & \\
\hline \multicolumn{7}{|c|}{ MK: 35-yr-old White female with anterior brainstem syndrome } \\
\hline \multicolumn{3}{|c|}{$107-132$} & \multicolumn{3}{|c|}{$193-206$} & \\
\hline 2 & \multicolumn{2}{|c|}{$\ldots \ldots \ldots \ldots \ldots \ldots$} & \multicolumn{2}{|c|}{ - . - . - . . . - } & & \\
\hline 11 & \multicolumn{2}{|c|}{ ICGKGLSATVTGGQKGRGS - - - . - - } & \multicolumn{2}{|c|}{ SAS IGSLCADARMY } & $2.2 ; 2.3$ & $\leftarrow \mathrm{CDMS}$ at $11 \mathrm{wk}$ \\
\hline 18 & \multicolumn{2}{|c|}{ - . . . . . . . . . . . . . . . } & \multicolumn{2}{|c|}{ - . . . . . . . . - } & & \\
\hline 26 & \multicolumn{2}{|c|}{ - . - . - . - - GGQKGRGSRGQHQA - } & \multicolumn{2}{|c|}{$\ldots-\ldots . .-\ldots$} & 2.4 & \\
\hline 52 & \multicolumn{2}{|c|}{ - . . . . . - - GQKGRGSRGQHQAH } & \multicolumn{2}{|c|}{$\ldots \ldots \ldots . . . . .}$. & 2.6 & \\
\hline
\end{tabular}

VS: 28-yr-old White female with internal capsule syndrome
$50-63$
$67-180$
210-244
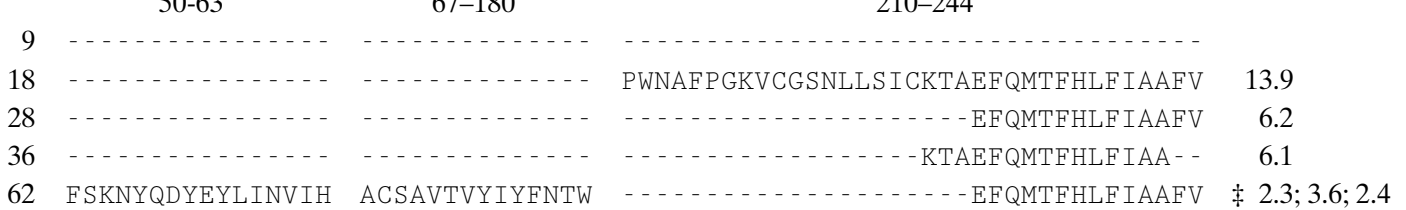

DL: 21-yr-old White female with partial transverse myelitis

$$
\text { 49-62 116-150 }
$$

2 -........... VTGGQKGRGSRGQHQAHSLERVCHCLGKWLGHPDK

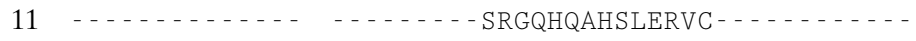

19 . . . . . . . . . . . . . . . . . . . . . .

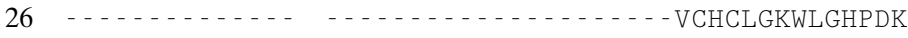

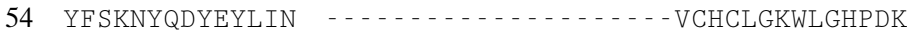

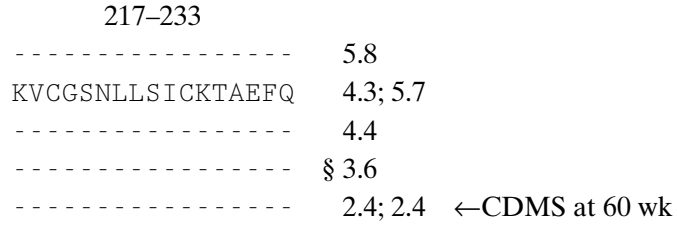

*PBMC from IMDS patients were serially evaluated for proliferative responses to an epitope-mapping series of 265 PLP 12-mer peptides. Test wells containing $15 \mu \mathrm{g} / \mathrm{ml}$ of a single PLP peptide were considered positive with a stimulation index $\geq 2.0$ and with a $\Delta \mathrm{cpm} \geq 500$ and at least two standard deviations above the mean of unstimulated control wells. Identification of PLP antigenic determinants required that positive proliferative responses be generated to at least three adjacent overlapping 12-mers. Control subjects were similarly evaluated by multiple serial testing. Patient JB was unable to have serial MRI scans due to morbid obesity. His initial scan was performed in an open MRI scanner. New T2-weighted unenhanced lesion(s) in the absence of new enhanced lesions. ${ }^{\S}$ New gadoteridol enhanced lesion(s). 
Table II. Serial PBMC Responses to PLP Peptides by Multicentric Monophasic IMDS Patients with Evidence of Prior Disease Activity*

\begin{tabular}{|c|c|c|}
\hline Wk (after initial symptoms) & PLP sequence & Stimulation index \\
\hline
\end{tabular}

ML: 30-yr-old Black female with monocular optic neuritis

\begin{tabular}{|c|c|c|}
\hline & $167-180$ & \\
\hline 1 & 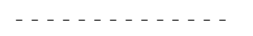 & \\
\hline 11 & מ & \\
\hline 19 & . & $\S$ \\
\hline 49 & ACSAVTVYIYFNTW & $\S 6.7$ \\
\hline
\end{tabular}

JG: 28-yr-old White male with partial transverse myelitis

\begin{tabular}{|c|c|c|c|c|}
\hline & $30-43$ & 133-168 & 180-193 & \\
\hline 3 & LFCGCGHEALTGTE & 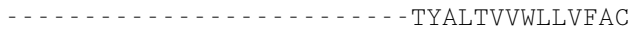 & - - - - & $\S 2.5 ; 2.7$ \\
\hline 11 & - n & 正, & - n & \\
\hline 19 & - n & (-1, & WTTCQSIAFPSKTS & $\S 5.5$ \\
\hline 32 & - n & -........ & - n- & $\S$ \\
\hline 42 & - n & - & 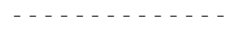 & $\S$ \\
\hline 62 & 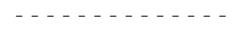 & SLERVCHCLGKWLGHP - . . . . . . . . . . . . . . & 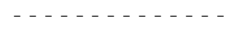 & 3.0 \\
\hline
\end{tabular}

LH: 41-yr-old White female with anterior brainstem syndrome

\begin{tabular}{|c|c|c|c|c|}
\hline & $131-148$ & 198-232 & $49-265$ & \\
\hline 9 & - & מ & - . & \\
\hline 13 & $-\ldots \ldots+\ldots$ & - & - & \\
\hline 22 & - & - - CADARMYGVLPWNAFPGKVCGSNLLS ICKTAEF & TLVSLLTFMIAATYNEA & $2.2 ; 2.3$ \\
\hline 31 & - - - - & SLCADARMYGVLPWNAFPGKVCG - - - - - - - & - & 2.2 \\
\hline 48 & - - - - & - & - & \\
\hline 68 & AHSLERVCHCLGKWLGHP & - & - & 2.3 \\
\hline
\end{tabular}

DB: 38-yr-old White female with monocular optic neuritis $143-157$

$192-241$

260-274

$\begin{array}{rrr}1 & \ldots & \end{array}$

LT: 28-yr-old White female with monocular optic neuritis 122-147

166-226

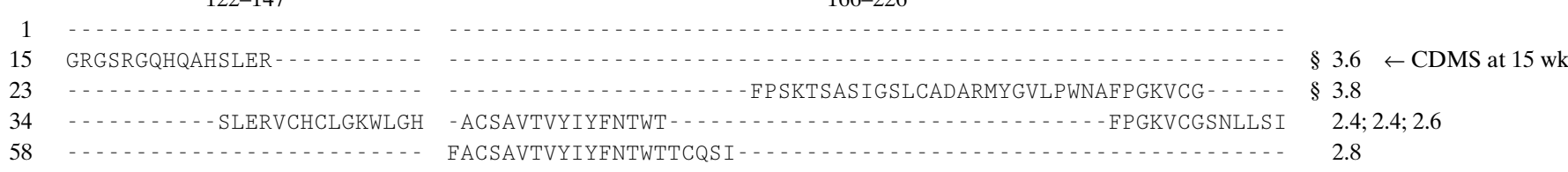

SW: 36-yr-old White female with monocular optic neuritis
50-63 102-129
210-252
$262-276$
18
26
51 FSKNYDYEYLINV - $\ldots \ldots \ldots \ldots \ldots \ldots \ldots \ldots$

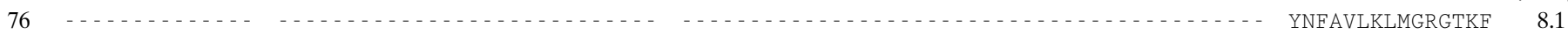
10 DYKTTICGKGLSATVT - $\ldots \ldots \ldots \ldots$

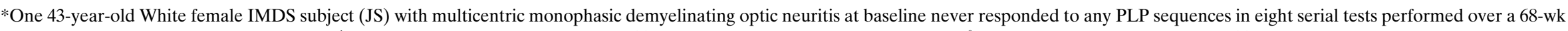
period from onset of neurologic symptoms. ${ }^{*}$ New T2-weighted unenhanced lesion(s) in the absence of new enhanced lesions. ${ }^{8}$ New gadoteridol enhanced lesion(s). 


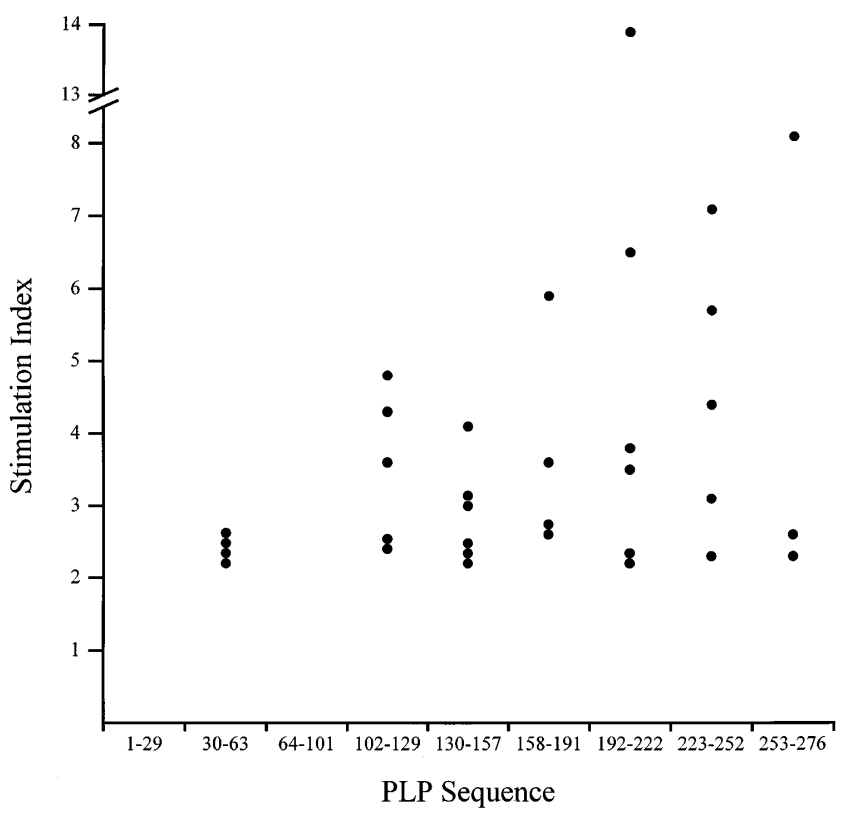

Figure 2. Responses of IMDS patients to PLP peptides. IMDS patients were serially tested to PLP epitope-mapping peptides over a 12-18-mo period. Dose-response profiles were also determined for reactivity to intact bovine PLP. With the notable exceptions of PLP 1-29 and 64-101, responses were directed against a broad range of determinants located within the remaining 276 amino acid sequence of the PLP molecule.

served in both groups of IMDS patients. Distinct examples include responses of monocentric monophasic IMDS patients (Table I) to p193-206 (SI = 2.3) by MK and p217-233 (SI = 5.7) by DL and responses of multicentric monophasic IMDS patients (Table II) to p30-43 (SI = 2.5), p155-168 (SI = 2.7), and p180-193 (SI = 5.5) by JG, p249-265 (SI = 2.3) by LH, and p50-63 (SI = 2.2) by SW. The failure to sustain reactivity to these peptides suggests that ephemeral responses may represent rapidly aborted autoimmunity.

Autoreactive profiles of control subjects. In contrast to the diversity and plasticity of PLP self recognition occurring in IMDS patients, no autoreactivity was observed in seven serially tested patients with OND, and only one ephemeral response $(\mathrm{KS}, \mathrm{p} 165-178, \mathrm{SI}=2.9)$ was evident in 13 age- and sex-matched NC subjects similarly tested (Table III). NC subjects included 10 females and 3 males with a mean age of $35 \mathrm{yr}$ (range, 20-54). In contrast to PLP peptide autoreactivity, responses to anti-CD3, tetanus toxoid, and M. tuberculosis H37RA did not vary extensively within individual IMDS, OND, and NC control subjects over the course of the study (data not shown). In addition, dose responses to freshly converted intact PLP showed infrequent reactivity with low stimulation indices (data not shown) reflecting the innate hydrophobicity and poor antigenicity of chloroform-extracted PLP (35).

Lack of consensus determinant recognition by patients sharing common MHC class II genes. DNA typing for HLA-DR and -DQ class II alleles showed that 6 out of 11 (55\%) IMDS subjects expressed the DRB1*15/DRB5*0101/DQB1*0602 haplotype known to be overrepresented in the MS population (36). However, analysis of serial responses to PLP epitopes revealed no common determinant recognized by all DRB1*15/ DRB5*0101/DQB1*0602 IMDS subjects (Table IV). The nearest to a consensus determinant was PLP 122-129 that activated responses by 4 out of 6 DRB1*15/DRB5*0101/ DQB1*0602 IMDS subjects (MK, DL, LT, SW, but not LH, $\mathrm{ML})$. Concordant responses to a common determinant were also not observed in IMDS subjects sharing the MHC class II haplotypes DQB1*03 (DB, JB, JG, LH, ML, VS), DRB1*03/ DRB3*0101/DQB1*02 (DB, MK, JS, SW), DRB4*01/DQB1*03 (JB, JG, LH, VS), and DRB1*04/DRB4*01/DQB1*03 (JB, JG, VS). However, PLP 180-193 was recognized by JG and partially recognized by LT, both of whom shared the DRB1*01/ DQB1*0501 MHC class II haplotype.

Correlation of serial PLP responses with measures of disease activity. Although distinct autoreactive profiles were evident in each IMDS patient group, we did not observe any precise one-to-one correlations between the development of responses to new PLP determinants and the appearance of new clinical or MRI measures of disease activity. In addition, the development of abrupt changes in PLP epitope recognition characteristic of multicentric monophasic IMDS patients did not appear to correspond to the frequency of MRI disease activity (Table II). Patients showing the highest levels of MRI disease activity (JG, DB, LT) developed patterns of PLP neoautoreactivity similar to those showing few new T2 or gadolinium-enhanced lesions ( $\mathrm{LH}, \mathrm{SW}$ ). It is worth noting that 4 out of $11(36 \%)$ IMDS patients (MK, DL, LT, DB) showed both sustained autoreactivity and progression to CDMS within the brief 12-18-mo period of the present study (Tables I and II). Moreover, two out of four patients (MK, DL) showing progression to CDMS were monocentric monophasic IMDS patients presumably at low risk $(5-10 \%)$ for disease progression (21-23), and one monocentric monophasic IMDS patient (MK) developed CDMS in the absence of any new MRI lesions. The apparent discrepancy between MRI and clinical measures of disease activity illustrates an important point. During early stages in the disease process, the development of symptoms associated with new MRI disease activity is to a great extent a matter of chance occurrence. Although our monocentric monophasic IMDS patients showed the expected low level of MRI disease activity, the higher than expected clinical activity may simply reflect chance occurrence in a small sample size.

\section{Discussion}

The present study shows that plasticity and diversity are predominant features of myelin $\mathrm{T}$ cell autoreactivity during the early development of MS. Moreover, it shows that differential self-recognition profiles occur within clinically distinct IMDS patient subgroups. Monocentric monophasic IMDS patients with no evidence of prior asymptomatic disease activity typically showed fully sustained autoreactivity involving recognition of long epitope-rich PLP regions, focusing and shifting of the targeted response to shorter core determinants, and subsequent spreading of the response to new PLP regions. In contrast, multicentric monophasic IMDS patients with evidence by MRI of prior asymptomatic CNS lesions often showed disrupted versions of this ordered autoreactivity with response profiles to a variety of PLP determinants.

Previous studies examining myelin self recognition in MS have relied almost exclusively on evaluating responses at one time point in patients with CDMS. Such single-testing approaches preclude the possibility of observing the innate de- 
Table III. Serial Responses of Control Subjects to an Epitope-mapping PLP Peptide Series

\begin{tabular}{|c|c|c|c|c|}
\hline Controls & Subject & Age/sex & Wk tested & Peptide response \\
\hline \multirow{8}{*}{$\begin{array}{l}\text { Other } \\
\text { neurologic } \\
\text { diseases } \\
(\text { OND })^{*}\end{array}$} & MF & $24 / \mathrm{F}$ & $1,10,65$ &,,--- \\
\hline & $\mathrm{DJ}$ & $27 / F$ & $1,13,65$ &,,--- \\
\hline & $\mathrm{SC}$ & $34 / \mathrm{F}$ & 1,69 &,-- \\
\hline & $\mathrm{AS}$ & $41 / \mathrm{M}$ & $1,11,61$ &,,--- \\
\hline & $\mathrm{HM}$ & $41 / \mathrm{M}$ & 1,65 &,-- \\
\hline & $\mathrm{JT}$ & $42 / \mathrm{M}$ & 1,9 &,-- \\
\hline & $\mathrm{GH}$ & $44 / \mathrm{F}$ & 1,13 &,-- \\
\hline & $\mathrm{HF}$ & $19 / \mathrm{M}$ & 1 &,- n.d. \\
\hline \multirow{13}{*}{$\begin{array}{l}\text { Normal } \\
\text { controls } \\
\text { (NC) }\end{array}$} & $\mathrm{CC}$ & $20 / \mathrm{F}$ & 1,9 &,-- \\
\hline & $\mathrm{CH}$ & $25 / \mathrm{F}$ & 1,9 &,-- \\
\hline & $\mathrm{BH}$ & $29 / \mathrm{M}$ & 1,9 &,-- \\
\hline & ND & $30 / \mathrm{F}$ & 1,9 &,-- \\
\hline & DB & $30 / \mathrm{F}$ & 1,9 &,-- \\
\hline & GA & $32 / \mathrm{F}$ & 1,10 &,-- \\
\hline & $\mathrm{JP}$ & $34 / \mathrm{F}$ & 1,9 &,-- \\
\hline & $\mathrm{JE}$ & $35 / \mathrm{M}$ & $1,9,64$ &,,--- \\
\hline & MT & $36 / \mathrm{F}$ & 1,9 &,-- \\
\hline & $\mathrm{MC}$ & $39 / \mathrm{F}$ & 1,10 &,-- \\
\hline & $\mathrm{KS}$ & $44 / F$ & $1,9,75$ & p165-178,-,- \\
\hline & $\mathrm{DG}$ & $47 / \mathrm{F}$ & $1,9,77$ &,,--- \\
\hline & HM & $54 / \mathrm{M}$ & $1,8,76$ &,,--- \\
\hline
\end{tabular}

*All OND control subjects had organic CNS injury: $M F$, left middle cerebral artery stroke; $D J$, encephalitis; $S C$ and $A S$, status post epilepsy surgery; $H M$, status post laminectomy for compression of the cervical spinal cord requiring surgery; $G H$, right thalamic hemorrhage; $J T$, left putamen hemorrhage; $H F$, brain swelling status post motor vehicle accident. velopmental instability of self recognition. Results of such previous studies have shown predominant HLA-DR-restricted T cell responses to PLP peptides p40-60 (37), p89-106 (38), p3049, and p180-199 (39). However, in the present study, none of these peptides showed any conspicuous domination for eliciting autoreactivity during the development of MS. This disparity may reflect the earlier stage of MS and autoimmune development examined in the current study, or alternatively, may reflect the limited number of peptides and reliance on $\mathrm{T}$ cell line expansion with intact PLP for defining peptide reactivity in the other studies.

The mechanisms involved in epitope focusing and shifting are presently unclear but may reflect a dynamic selection/inhibition process in which autoreactive $\mathrm{T}$ cells respond sequentially to different determinants within an epitope-rich region of a self antigen. Likewise, the mechanism underlying the disruption of sustained autoreactivity observed in multicentric monophasic IMDS patients is also presently unclear. Peripheral clonal deletion (40), perhaps due to apoptosis $(41,42)$, may possibly explain the observed disruption. Alternatively, these clinically more active patients may have decreased numbers of determinant-specific autoreactive $\mathrm{T}$ cells in their peripheral blood compartment due to trapping of autoreactive $\mathrm{T}$ cells in active CNS lesions. This view is supported by the appearance of numerous new CNS lesions in this high risk group. However, recent studies have indicated that immunologic changes in PBMC reactivity during MS appear to be the result of qualitative rather than quantitative changes. Analysis of both mRNA and T cell clones derived from PBMC has shown that during exacerbation of MS, autoreactivity correlated with $\mathrm{T}$ cell production of the proinflammatory cytokines TNF $\beta$ and IFN $\gamma$ whereas remission was associated with production of the regulatory cytokines IL-10 and TGF $\beta(43,44)$. Thus, the exac-

Table IV. Consensus PLP Sequence Recognition by IMDS Patients Sharing MHC Class II Genes*

\begin{tabular}{|c|c|c|c|}
\hline Class II haplotype & Common reactant PLP sequence & Responders & Nonresponders \\
\hline \multirow[t]{7}{*}{ DRB1*15/DRB5*0101/DQB1*0602 $(n=6)$} & p50-62 & DL,SW & LH,MK,ML,LT \\
\hline & p122-129 & MK,DL,LT,SW & $\mathrm{LH}, \mathrm{ML}$ \\
\hline & p131-147 & LH,DL,LT & MK,ML,SW \\
\hline & p167-180 & ML,LT & LH,MK,DL,SW \\
\hline & p198-206 & $\mathrm{LH}, \mathrm{MK}, \mathrm{LT}$ & DL,ML,SW \\
\hline & p210-220 & LH,LT,SW & MK,DL,ML \\
\hline & p217-232 & LH,DL,SW & MK,ML,LT \\
\hline \multirow[t]{5}{*}{$\mathrm{DQB} 1 * 03(n=6)$} & p143-148 & DB,JB,JG,LH & ML,VS \\
\hline & p167-180 & $\mathrm{ML}, \mathrm{VS}$ & $\mathrm{DB}, \mathrm{JB}, \mathrm{JG}, \mathrm{VS}$ \\
\hline & $\mathrm{p} 210-232$ & $\mathrm{DB}, \mathrm{LH}, \mathrm{VS}$ & $\mathrm{JB}, \mathrm{JG}, \mathrm{ML}$ \\
\hline & p228-241 & $\mathrm{DB}, \mathrm{VS}$ & $\mathrm{JB}, \mathrm{JG}, \mathrm{LH}, \mathrm{ML}$ \\
\hline & p260-265 & $\mathrm{DB}, \mathrm{LH}$ & $\mathrm{JB}, \mathrm{JG}, \mathrm{ML}, \mathrm{VS}$ \\
\hline \multirow[t]{4}{*}{ DRB1*03/DRB3*0101/DQB1*02 $(n=4)$} & p107-129 & MK,SW & $\mathrm{DB}, \mathrm{JS}$ \\
\hline & p193-206 & $\mathrm{DB}, \mathrm{MK}$ & JS,SW \\
\hline & $\mathrm{p} 210-241$ & $\mathrm{DB}, \mathrm{SW}$ & MK,JS \\
\hline & p262-274 & $\mathrm{DB}, \mathrm{SW}$ & MK,JS \\
\hline \multirow[t]{2}{*}{ DRB4*01/DQB1 $* 03(n=4)$} & p133-148 & $\mathrm{JB}, \mathrm{JG}, \mathrm{LH}$ & VS \\
\hline & p210-232 & LH,VS & $\mathrm{JB}, \mathrm{JG}$ \\
\hline DRB1*04/DRB4*01/DQB1 $* 03(n=3)$ & p133-148 & $\mathrm{JB}, \mathrm{JG}$ & VS \\
\hline $\mathrm{DRB} 1 * 01 / \mathrm{DQB} 1 * 0501(n=2)$ & p180-193 & $\mathrm{JG}, \mathrm{LT}$ & - \\
\hline
\end{tabular}

*DNA typing was performed by sequence-specific oligonucleotide probe typing (PCR-SSOP). No common PLP determinants were recognized by two IMDS patients $(D B, M L)$ sharing the DRB $3 * 02 / \mathrm{DQB} 1 * 03$ haplotype. 
erbating/remitting pattern of disease activity in MS appears to be associated, respectively, with proinflammatory/inhibitory cytokine surges rather than with fluctuations in clonal frequency of autoreactive PBMC.

The basis for ephemeral autoreactivity in the development of MS is also presently unknown. However, it is difficult to dismiss ephemeral reactivity as artifact particularly in light of the high stimulation index of some ephemeral responses (e.g., SI $=$ 5.7 for $\mathrm{p} 180-193$ by $\mathrm{JG}$ and SI $=5.5$ for $\mathrm{p} 217-233$ by DL) and the profusion of ephemeral autoreactivity in IMDS patients compared with controls. A variety of immunoregulatory mechanisms have been implicated in the abrogation of myelin self recognition in murine EAE including anti- $\mathrm{V}_{\beta}$ reactivity, clonal anergy, clonal deletion, $\mathrm{CD}^{+}$and $\mathrm{Th} 2$ regulatory $\mathrm{T}$ cells, apoptosis, migration of autoreactive $\mathrm{T}$ cells from peripheral blood, and innocent bystander suppression (reviewed in references 1 and 2). The distinct rapid vs delayed dual kinetics in the abrogation of ongoing autoimmunity suggest that more than one regulatory mechanism may be involved in down-regulating myelin self recognition.

It is worth noting that the ephemeral quality of much of the observed autoreactivity does not appear to reflect innate features of the determinants per se but instead represents inherent characteristics of responses to the determinants. This may best be evident in the purely ephemeral response to p193-206 by MK but the partially sustained response to its truncated counterpart p198-206 by LH. Thus, the rapid disappearance of ephemeral autoreactivity implies that effective inhibitory immunoregulatory mechanisms are intact and active. This view is supported by the observed changes that occur in $\mathrm{T}$ cell repertoire restriction by optic neuritis patients who ultimately develop MS (45).

The observed diversity and plasticity of self-recognition in the development of MS may have profound implications on the development of effective and enduring peptide-specific therapies. Native encephalitogenic determinants of myelin proteins have been shown to be therapeutic in the prevention or treatment of EAE when used to induce tolerance $(14,46)$ or Th2 immune deviation (47), whereas substituted analogues of native determinants have been implicated in EAE therapy as agonists (48), partial agonists (49), and antagonists (50) of the $\mathrm{T}$ cell receptor. The extent of self recognition plasticity occurring in the early development of MS suggests that peptidebased antigen-specific treatment at early stages may have to embrace a "moving target" strategy in which the selection of remedial peptides accommodates the shifting patterns of defined self-recognition cascades.

The evolving nature of self-recognition during the early development of MS may offer both an opportunity for targeting immunotherapy as well as a means for monitoring the effectiveness of such therapies. However, it remains to be determined whether autoreactivity stabilizes with time or maintains a high level of diversity and plasticity during subsequent progression of MS. Ongoing studies may decide this issue and may also shed light on mechanisms of aborted autoreactivity by determining whether prior abrogated responses reappear or remain undetected.

\section{Acknowledgments}

This work was supported by National Multiple Sclerosis Society grant RG-2768 (V.K. Tuohy) and by National Institutes of Health grant
NS-36054 (V.K. Tuohy). Additional support for MRI testing was provided by Bracco Diagnostics, Inc., Princeton, NJ (R.P. Kinkel).

\section{References}

1. Martin, R., H.F. McFarland, and D.E. McFarlin. 1992. Immunological aspects of demyelinating diseases. Annu. Rev. Immunol. 10:153-187.

2. Steinman, L. 1996. Multiple sclerosis: a coordinated immunological attack against myelin in the central nervous system. Cell. 85:299-302.

3. Baxevanis, C.N., G.J. Reclos, C. Servis, E. Anastasopoulos, P. Arsenis, A. Katsiyiannis, N. Matikas, J.D. Lambris, and M. Papamichail. 1989. Peptides of myelin basic protein stimulate $\mathrm{T}$ lymphocytes from patients with multiple sclerosis. J. Neuroimmunol. 22:23-30.

4. Richert, J.R., E.D. Robinson, G.E. Deibler, R.E. Martenson, L.J. Dragovic, and M.W. Kies. 1989. Evidence for multiple human T cell recognition sites on myelin basic protein. J. Neuroimmunol. 23:55-66.

5. Allegretta, M., J.A. Nicklas, S. Sriram, and R.J. Albertini. 1990. T cells responsive to myelin basic protein in patients with multiple sclerosis. Science (Wash. DC). 247:718-721.

6. Ota, K., M. Matsui, E.L. Milford, G.A. Mackin, H.L. Weiner, and D.A. Hafler. 1990. T-cell recognition of an immunodominant myelin basic protein epitope in multiple sclerosis. Nature (Lond.). 346:183-187.

7. Pette, M., K. Fujita, D. Wilkinson, D.M. Altmann, J. Trowsdale, G. Giegerich, A. Hinkkanen, J.T. Epplen, L. Kappos, and H. Wekerle. 1990. Myelin autoreactivity in multiple sclerosis: recognition of myelin basic protein in the context of HLA-DR2 products by T lymphocytes of multiple sclerosis patients and healthy donors. Proc. Natl. Acad. Sci. USA 87:7968-7972.

8. Martin, R., U. Utz, J.E. Coligan, J.R. Richert, M. Flerlage, E. Robinson, R. Stone, W.E. Biddison, D.E. McFarlin, and H.F. McFarland. 1992. Diversity in fine specificity and $\mathrm{T}$ cell receptor usage of the human CD4+ cytotoxic $\mathrm{T}$ cell response specific for the immunodominant myelin basic protein peptide 87-106. J. Immunol. 148:1359-1366.

9. Sun, J.-B., T. Olsson, W.-Z. Wang, B.-G. Xiao, V. Kostulas, S. Fredrikson, H.-P. Ekre, and H. Link. 1991. Autoreactive T and B cells responding to myelin proteolipid protein in multiple sclerosis and controls. Eur. J. Immunol. 21:1461-1468.

10. Trotter, J.L., W.F. Hickey, R.C. van der Veen, and L. Sulze. 1991. Peripheral blood mononuclear cells from multiple sclerosis patients recognize myelin proteolipid protein and selected peptides. J. Neuroimmunol. 33:55-62.

11. Chou, Y.K., D.N. Bourdette, H. Offner, R. Whitham, R.Y. Wang, G.A. Hashim, and A.A. Vandenbark. 1992. Frequency of T cells specific for myelin basic protein and myelin proteolipid protein in blood and cerebrospinal fluid in multiple sclerosis. J. Neuroimmunol. 38:105-113.

12. Kerlero de Rosbo, N., R. Milo, M.B. Lees, D. Burger, C.C. Bernard, and A. Ben-Nun. 1993. Reactivity to myelin antigens in multiple sclerosis. Peripheral blood lymphocytes respond predominantly to myelin oligodendrocyte glycoprotein. J. Clin. Invest. 92:2602-2608.

13. Zhang, Y., D. Burger, G. Saruhan, M. Jeannet, and A.J. Steck. 1993. The T-lymphocyte response against myelin-associated glycoprotein and myelin basic protein in patients with multiple sclerosis. Neurology. 43:403-407.

14. Clayton, J.P., G.M. Gammon, D.G. Ando, D.H. Kono, L. Hood, and E.E. Sercarz. 1989. Peptide-specific prevention of experimental allergic encephalomyelitis. Neonatal tolerance induced to the dominant $\mathrm{T}$ cell determinant of myelin basic protein. J. Exp. Med. 169:1681-1691.

15. McCarron, R.M., R.J. Fallis, and D.E. McFarlin. 1990. Alterations in T cell antigen specificity and class II restriction during the course of chronic relapsing experimental allergic encephalomyelitis. J. Neuroimmunol. 29:73-79.

16. Perry, L.L., E. Barzaga-Gilbert, and J.L. Trotter. 1991. T cell sensitization to proteolipid protein in myelin basic protein-induced relapsing experimental allergic encephalomyelitis. J. Neuroimmunol. 33:7-15.

17. Lehmann, P.V., T. Forsthuber, A. Miller, and E.E. Sercarz. 1992. Spreading of $\mathrm{T}$ cell autoimmunity to cryptic determinants of an autoantigen. Nature (Lond.). 358:155-157.

18. Cross, A.H., V.K. Tuohy, and C.S. Raine. 1993. Development of reactivity to new myelin antigens during chronic relapsing autoimmune demyelination. Cell. Immunol. 146:261-269.

19. McRae, B.L., C.L. Vanderlugt, M.C. Dal Canto, and S.D. Miller. 1995. Functional evidence for epitope spreading in the relapsing pathology of experimental autoimmune encephalomyelitis. J. Exp. Med. 182:75-85.

20. Yu, M., J.M. Johnson, and V.K. Tuohy. 1996. A predictable sequential determinant spreading cascade invariably accompanies progression of experimental autoimmune encephalomyelitis: A basis for peptide-specific therapy after onset of clinical disease. J. Exp. Med. 183:1777-1788.

21. Morrissey, S.P., D.H. Miller, B.E. Kendall, D.P. Kingsley, M.A. Kelly, D.A. Francis, D.G. MacManus, and W.I. McDonald. 1993. The significance of brain magnetic resonance imaging abnormalities at presentation with clinically isolated syndromes suggestive of multiple sclerosis. Brain. 116:135-146.

22. Filippi, M., M.A. Horsfield, S.P. Morrissey, D.G. MacManus, P. Rudge, W.I. McDonald, and D.H. Miller. 1994. Quantitative brain MRI lesion load predicts the course of clinically isolated syndromes suggestive of multiple sclerosis. Neurology. 44:635-641. 
23. Beck, R.W., P.A. Cleary, J.D. Trobe, D.I. Kaufman, M.J. Kupersmith, D.W. Paty, and C.H. Brown. 1993. The effect of corticosteroid for acute optic neuritis on the subsequent development of multiple sclerosis. N. Eng. J. Med. 329:1764-1769.

24. Poser, C.M., D.W. Paty, L. Scheinberg, W.I. McDonald, F.A. Davis, G.C. Ebers, K.P. Johnson, W.A. Sibley, D.H. Silberberg, and W.W. Tourtellotte. 1983. New diagnostic criteria for multiple sclerosis: guidelines for research protocols. Ann. Neurol. 13:227-231.

25. Milner, R.J., C. Lai, K.-A. Nave, D. Lenoir, J. Ogata, and J.G. Sutcliffe. 1985. Nucleotide sequences of two mRNAs for rat brain myelin proteolipid protein. Cell. 42:931-939.

26. Macklin, W.B., C.W. Campagnoni, P.L. Deininger, and M.V. Gardinier. 1987. Structure and expression of the mouse myelin proteolipid protein gene. $J$. Neurosci. Res. 18:383-394.

27. Geysen, H.M., S.J. Rodda, T.J. Mason, G. Tribbick, and P.G. Schoofs. 1987. Strategies for epitope analysis using peptide synthesis. J. Immunol. Methods. 102:259-274.

28. Maeji, N.J., A.M. Bray, and H.M. Geysen. 1990. Multi-pin peptide synthesis strategy for T cell determinant analysis. J. Immunol. Methods. 134:23-33.

29. Gammon, G., H.M. Geysen, R.J. Apple, E. Pickett, M. Palmer, A. Ametani, and E.E. Sercarz. 1991. T cell determinant structure: cores and determinant envelopes in three mouse major histocompatibility complex haplotypes. J. Exp. Med. 173:609-617.

30. Bhardwaj, V., V. Kumar, I.S. Grewal, T. Dao, P.V. Lehmann, H.M. Geysen, and E.E. Sercarz. 1994. T cell determinant structure of myelin basic protein in B10.PL, SJL/J, and their $\mathrm{F}_{1}$ s. J. Immunol. 152:3711-3719.

31. Kaufman, D.L., M. Clare-Salzler, J. Tian, T. Forsthuber, G.S. Ting, P. Robinson, M.A. Atkinson, E.E. Sercarz, A.J. Tobin, and P.V. Lehmann. 1993. Spontaneous loss of T-cell tolerance to glutamic acid decarboxylase in murine insulin-dependent diabetes. Nature (Lond.). 366:69-72.

32. Novotny, J., R.E. Bruccoleri, W.D. Carlson, M. Handschumacher, and E. Haber. 1987. Antigenicity of myohemerythrin. Science (Wash. DC). 238: 1584-1586.

33. Folch, J., M. Lees, and G.H. Sloane Stanley. 1957. A simple method for the isolation and purification of total lipides from animal tissues. J. Biol. Chem. 226:497-509.

34. Tuohy, V.K., Z. Lu, R.A. Sobel, R.A. Laursen, and M.B. Lees. 1989. Identification of an encephalitogenic determinant of myelin proteolipid protein for SJL mice. J. Immunol. 142:1523-1526.

35. Tuohy, V.K. 1994. Peptide determinants of myelin proteolipid protein (PLP) in autoimmune demyelinating disease: a review. Neurochem. Res. 19: 935-944.

36. Allen, M., M. Sandberg-Wollheim, K. Sjogren, H.A. Erlich, U. Petterson, and U. Gyllensten. 1994. Association of susceptibility to multiple sclerosis in Sweden with HLA class II DRB1 and DQB1 alleles. Human Immunol. 39: $41-48$

37. Pelfrey, C.M., J.L. Trotter, L.R. Tranquill, and H.F. McFarland. 1993. Identification of a novel $\mathrm{T}$ cell epitope of human proteolipid protein (residues 40-60) recognized by proliferative and cytolytic $\mathrm{CD}^{+} \mathrm{T}$ cells from multiple sclerosis patients. J. Neuroimmunol. 46:33-42.
38. Pelfrey, C.M., J.L. Trotter, L.R. Tranquill, and H.F. McFarland. 1994. Identification of a second $\mathrm{T}$ cell epitope of human proteolipid protein (residues 89-106) recognized by proliferative and cytolytic $\mathrm{CD}^{+} \mathrm{T}$ cells from multiple sclerosis patients. J. Neuoroimmunol. 53:153-161.

39. Markovic-Plese, S., H. Fukaura, J. Zhang, A. Al-Sabbagh, S. Southwood, A. Sette, V.K. Kuchroo, and D.A. Hafler. 1995. T cell recognition of immunodominant and cryptic proteolipid protein epitopes in humans. J. Immunol. 155:982-992.

40. Zhang, J., C. Vandevyver, P. Stinissen, and J. Raus. 1995. In vivo clonotypic regulation of human myelin basic protein-reactive $\mathrm{T}$ cells by $\mathrm{T}$ cell vaccination. J. Immunol. 155:5868-5877.

41. Pelfrey, C.M., L.R. Tranquill, S.A. Boehme, H.F. McFarland, and M.J. Lenardo. 1995. Two mechanisms of antigen-specific apoptosis of myelin basic protein (MBP)-specific T lymphocytes derived from multiple sclerosis patients and normal individuals. J. Immunol. 154:6191-6202.

42. Tanaka, H., K. Ota, M. Ikusaka, M. Ejima, and S. Maruyama. 1995. Expression of Fas-antigen on T cells in multiple sclerosis. Rinsho Shinkeigaku Clin. Neurol. (Tokyo). 35:299-301.

43. Rieckmann, P., M. Albrecht, B. Kitze, T. Weber, H. Tumani, A. Broocks, W. Luer, A. Helwig, and S. Poser. 1995. Tumor necrosis factor-alpha messenger RNA expression in patients with relapsing-remitting multiple sclerosis is associated with disease activity. Ann. Neurol. 37:82-88.

44. Correale, J., W. Gilmore, M. McMillan, S. Li, K. McCarthy, T. Le, and L.P. Weiner. 1995. Patterns of cytokine secretion by autoreactive proteolipid protein-specific $\mathrm{T}$ cell clones during the course of multiple sclerosis. J. Immunol. 154:2959-2968.

45. Soderstrom, M., H. Link, S. Fredrikson, and J.-B. Sun. 1994. Optic neuritis and multiple sclerosis: the $\mathrm{T}$ cell repertoires to myelin proteins and MBP peptides change with time. Acta Neurol. Scand. 90:10-18.

46. Kennedy, M.K., L.-J. Tan, M.C. Dal Canto, V.K. Tuohy, Z. Lu, J.L. Trotter, and S.D. Miller. 1990. Inhibition of murine relapsing experimental autoimmune encephalomyelitis by immune tolerance to proteolipid protein (PLP) and its encephalitogenic peptides. J. Immunol. 144:909-915.

47. Kuchroo, V.K., M.P. Das, J.A. Brown, A.M. Ranger, S.S. Zamvil, R.A. Sobel, H.L. Weiner, N. Nabavi, and L.H. Glimcher. 1995. B7-1 and B7-2 costimulatory molecules activate differentially the Th1/Th2 developmental pathways: application to autoimmune disease therapy. Cell. 80:707-718

48. Samson, M.F., and D.E. Smilek. 1995. Reversal of acute experimental autoimmune encephalomyelitis and prevention of relapses by treatment with a myelin basic protein peptide analogue modified to form long-lived peptideMHC complexes. J. Immunol. 155:2737-2746.

49. Brocke, S., K. Gijbels, M. Allegretta, I. Ferber, C. Piercy, T. Blankenstein, R. Martin, U. Utz, N. Karin, D. Mitchell, et al. 1996. Treatment of experimental encephalomyelitis with a peptide analogue of myelin basic protein. $\mathrm{Na}$ ture (Lond.). 379:343-346.

50. Franco, A., S. Southwood, T. Arrhenius, V.K. Kuchroo, H.M. Grey, A. Sette, and G.Y. Ishioka. 1994. T cell receptor antagonist peptides are highly effective inhibitors of experimental allergic encephalomyelitis. Eur. J. Immunol. 24:940-946. 